$$
\text { دور التَّفاسير في ترجمة معاني القرآن الكريم }
$$

Nicolás Roser Nebot. Universidad de Málaga

Recepción: 16.12.2018 | Aceptado: 21.10.2019

Correspondencia a través de ORCID: Nicolás Roser Nebot

(iD 0000-0002-4732-4366

Citar: Roser, N. (2019). El papel de la exégenis en la traducción del Corán. REIDOCREA, 8, 231-249.

\title{
El papel de la exégenis en la traducción del Corán
}

Resumen: Antecedentes: En la actividad traductora existen unas reglas generales que, en la práctica, dan lugar a soluciones diferentes a tenor de los textos y de las situaciones. Éste es el espacio donde las capacidades y habilidades del traductor aparecen en toda su dimensión con objeto de lograr una traducción que sea capaz de incluir todos los significados que se hallan en el original. Objetivos e hipótesis: Desde esta premisa, la traducción del Corán necesita de unos procedimientos específicos, atendiendo a la transcendencia de sus contenidos y de la belleza literaria de sus continentes. Ni unos ni otros admiten ser deslindados en el momento de ser traducidos; y ello siempre en la medida de lo posible. Por esta razón, quien desee traducir los versículos coránicos, ya sea una parte o su totalidad, deberá elegir los medios adecuados para tal fin. Método: En este caso, uno de esos medios está constituido por la exégesis coránica en árabe. En esta exégesis, hay indicaciones esclarecedoras y explicaciones indispensables sobre las palabras, frases y expresiones que configuran los versículos del Corán. Resultados: Ninguna traducción puede ser realizada sin entender plenamente el original y apreciar su realidad única en relación con otros textos. La razón principal de los errores y equivocaciones en la traduccíon del Corán provienen de la no comprensión o de la mala comprensíon del texto original. Conclusiones: La exégesis coránica en árabe proporciona un instrumento primordial para la comprensión del propio Corán y ayuda a evitar los errores y las equivocaciones en su traducción.

\section{Palabras clave: Corán | Traducción}

\section{The roll of the Qur'anic exegesis in Qur'an}

Abstract: Background: In translation work there are general rules that turn into various translation solutions in praxis depending on specific situations and texts. This is the space where the translator's capabilities and skills appear properly to do a successful translation including all of the meanings we can find in the original. Aims and hypothesis: With this in mind, the translation of Qur'an's meanings needs concrete procedures on the basis of the importance of the contents and the literary beauty of the continents, both couldn't be separated at the time translation as far as possible. Therefore, who wants to do the translation of all the Qur'anic verses or some of them has to choose the suitable means. Method: In this case, one of those means is the Muslim Qur'anic exegesis in Arabic. In this exegesis, there are significances and explanations about the words, phrases and utterances which set up the Qur'anic verses. Results: Not translation is possible without understanding the original and appreciating its single reality before. The main reason of the failures in the translation of the Qur'anic contents is because they are misunderstood. Conclusions: The Muslim Qur'anic exegesis in Arabic enhances to understand the Qur'an's text and provides utilities to avoid the failures in its translation.

Keywords: Qur'an | Translation

$$
\begin{aligned}
& \text { العنوان: دور التَّاسيرفي ترجمة معاني القرآن الكريم } \\
& \text { المخلص: } \\
& \text { المنطلق: للترجمة قو انين عامة يتم تطبيقها بأساليب خاصة في ظروف معينة، وفي ذلك النطبيق تتجلى قدرة المنرجم وكفاءته في نقل يؤدي الغرض } \\
& \text { ويستوفي معاني الأصل. } \\
& \text { الأطروحة: من هذا المنطلق ونظرًا لأهميَّة المحتوى وجمالية اللَّظظ فإن ترجمة معاني القرآن تتطلب أساليب خاصيّة، فلا يجوز الفصل بينهما بقدر } \\
& \text { المستطاع ساعة الترجمة. } \\
& \text { المنهج: ومن ذللك فعلى من يقوم بترجمة معاني القرآن (جميع آياته أو بعضها) اختبار الآليات الملائمة. ومن بين هذه الآليات ما جاء في التفاسبر من } \\
& \text { دلالة وشرح عن الألفاظ و الجمل و العبار ات المكونة لكئل للآيات القر آنية. }
\end{aligned}
$$




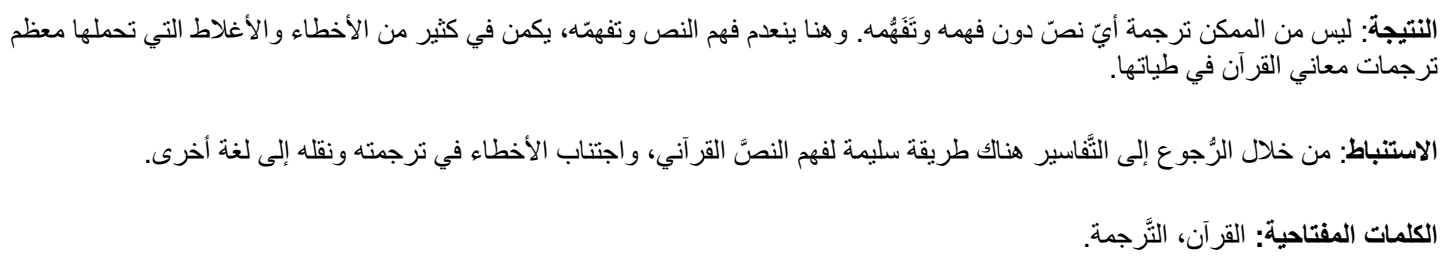

المقدمة

لقد لاحظنا في أثثاء قراءاتتا لمختلف ترجمات معاني القرآن إلى لغات متعددة وبخاصة التي هي باللُّة الإسبانية، أنَّ هناك أخطاء فادحة في نقل معاني الألفاظ والعبارات من العربية إلى تلك اللغات. وتُشّوّه تلك الأخطاء

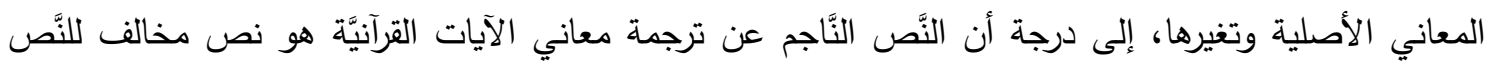

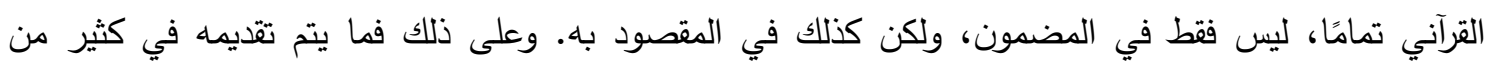

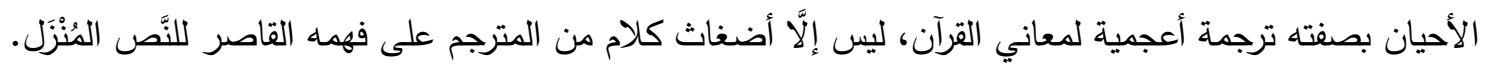

وليس هذا الوضع حكرًا على المستشرقين فقط بالرغم من أنهم يكونون أغلبية المترجمين الذين يخطئون في

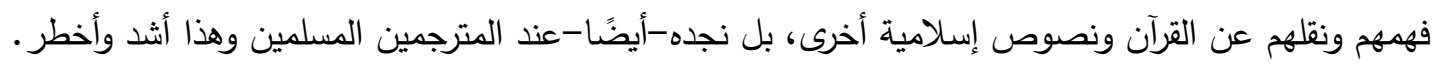

وكذلك الخطر في وجود ترجمات مغلوطة لمعاني القرآن كامن في أن كثيرًا من المسلمين الناطقين بغير

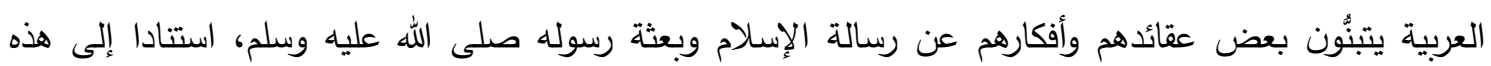
الترجمات لمعاني القرآن. وفي الوقت نفسه يصنع خصوم الإسلام وأعداؤه العديد من مغالطاتهم له ولتاريخه ولحضارته ولمجتمعاته اعتمادا على هذه الترجمات المشوهة عن مضامين الذّكر الحكيم.

وغالبا ما تتبعث هذه الأخطاء في ترجمة معاني القرآن عن الضّعف وعدم التَّكُنْ إما من اللغة العربية

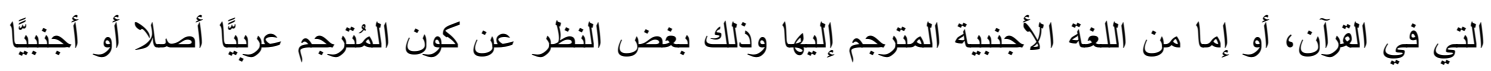

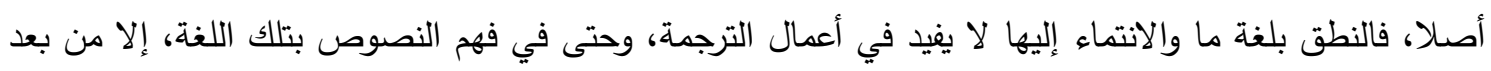

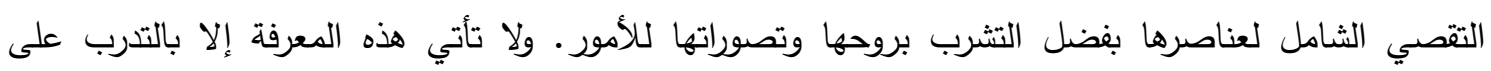
استيعاب نصوص تلك اللغة وإدراك طريقة استخدامها عند الناطقين بها قديما وحديثا مثلما يقول ابن خلدون بالنسبة

$$
\text { إلى العربية (المقدمة: ج } 3 \text { ص 1285-1286): }
$$

"ووجه التعليم لمن يبتغي هذه الملكة [أي اللُّة العربيَّة]، ويروم تحصيلها أن يأخذ نفسه بحفظ كلامهم القديم الجاري

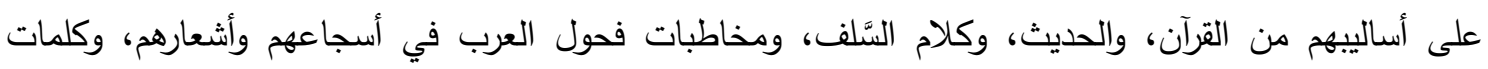
المولدين أيضًا في سائر فنونهم، حتى يتنزل لكثرة حفظه لكلامهح من المنظوم والمنثور منزلة من نشأ بينهم ولقن

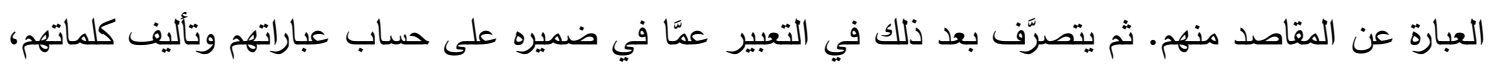
وماوعاه وحفظه من أساليبهح وترتيب ألفاظهه، فتحصل له هذه الملكة، بهذالحفظ والاستعمال، ويزداد بكثرتهما رسوخًا وقوَّة، ويحتاج مع ذلك إلى سلامة الطبع والتفهم الحسن لمنازع العرب وأساليبهم في التراكيب ومراعاة التطبيق

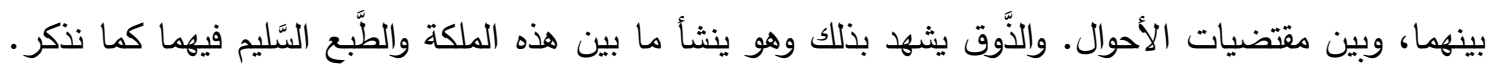

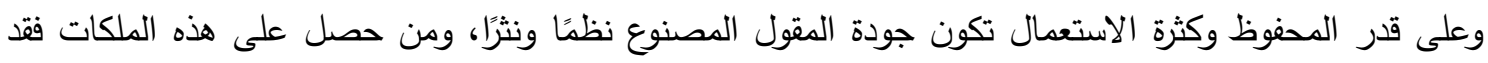


حصل على لغة مُضَر وهو النَّاقد البصير بالبلاغة فيها، وهكذا ينبغي أن يكون تعلمها. والله يهدي من يثاء بفضله وكرمها.

وفي قضية ترجمة معاني القرآن يضاف إلى إجادة اللغة العربية في نحوها وصرفها وألفاظها الإلمام بما بلغنا من تفاسير العلماء للقرآن الكريم على مدى التاريخ الإسلامي. فمن يريد ترجمة معانيه إلى لغات أخدات أخرى خدمة

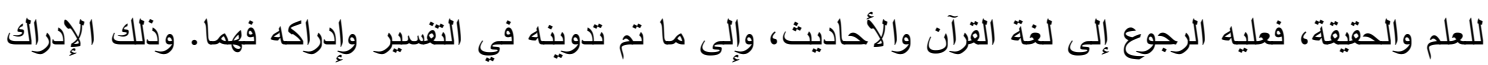
هو الذي سيضمن له نقل معاني القرآن إلى لغة أخرى بطريقة مؤاتية.

وهناك عاملان آخران لا يجوز أن يفوتانا في عملية ترجمة معاني القرآن: أولهما مراعاة عقلية القوم

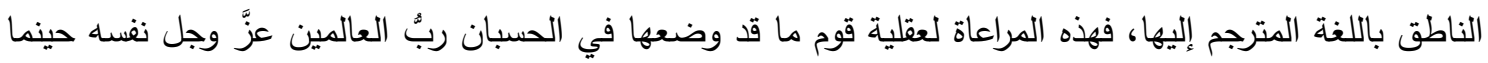

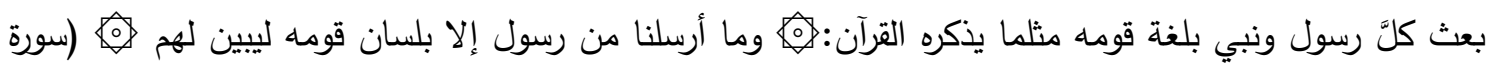
إبراهيم، 4). وثانيهما مراعاة الظروف المحيطة بقُرَّاء الترجمة. ومن هذا المنطلق لقد فصّل جلَّ جلاله خطابه وآياته

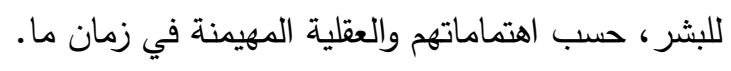

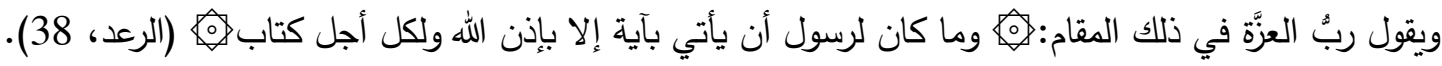

والعامل الأخير الذي لا بدَّ منه في القيام بترجمة معاني القرآن، هو الاطلاع على ما تأتت به العلوم

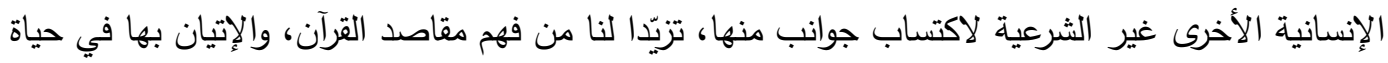

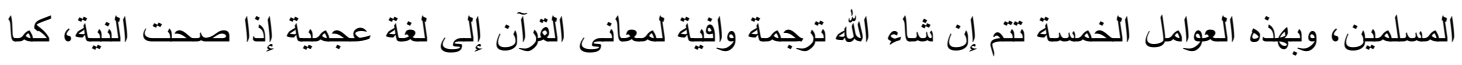
يقول الإمام مالك في طلب العلم.

\section{خيانة المُترجمين وأمانة المُفسرّين}

هناك مثل إيطالي مشهور في قضية الترجمة يقول: "إن المترجم خائن" نظرا إلى قرابة النطق بين لفظ "ترادوكتوري" (مترجم) ولفظ "تراديتوري" (خائن)، ومن هذا المنطلق جاءت الفكرة السَّائدة عند الغربيين، ومن يزاول صناعة الترجمة، أو من يحتاج إليها ويستخدمها، أنَّ التَّرجمة سواء أكانت كتابة أم نطقًا، إذ تحتوي على قدر لا بأس به من الخيانة -أي من تشويه أو تحييد المعنى الوارد في الكلام المنقول من لغة إلى أخرى-وهذه الفكرة ظالمة للمترجم ولعملية الترجمة،وإمكانية حدوث هذه الترجمة. ولتأكيد الظُّلم المكتوم في هذا التَّصوُر عن الترجمة

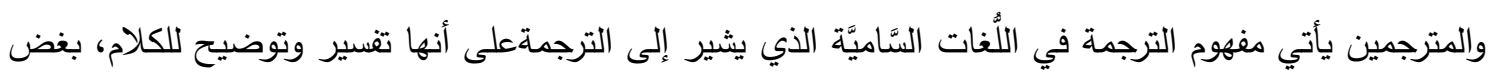
النظر عن وقوع ذلك التفسير في اللغة نفسها، أو في لغة مغايرة للغة الأولى التي صدر فيها الكلام. ومن يقوم بذلك التفسير هو التُرجمان أي موضح ومفهم مقصود الكلام الذي احتاج إلى تقسير لأساب عدة: إما لاختصاصه، وإما لإثكاله، وإما لتشابهه بكلام سواه، وإما لمستوى ثقافي ولغوي غير لائق عند السامع أو القارئ. 
إنَّ التَّرجمة هي كلمة مُشتقَّة من الكلمة الآرامية "ترجوم" (ترغوم في النطق) بمعنى التَّسير والتَّوضيح، وبهذا المعنى نجدها في جميع اللُّات المَّاميَّة، ومنها العربية (ترجمة)، ومنها العبرية (ترغوم مثلما هو في الأصل).

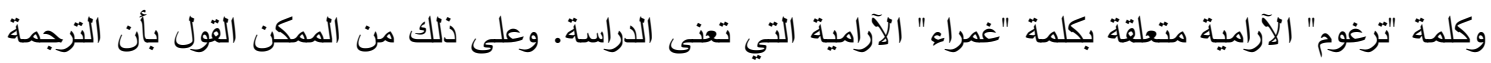
في أصلها وفيما جاء في تعريبها و "تعبريَّتها أو تعبيرها".

إن صحَّ التَّبعبر، تحمل معنى دراسة الكلام الذي مراده ترجمته وتفسيره وتوضيحه. والغربب أن كلمة "ترجوم" وفعل "ترجم" بالآرامية وبالعبرية لم يردا في التوراة التي تستخدم دائما فعل "فسر" (بالعبرية "فشر") أي: شرح المعنى بنفس اللغة أو لغة أخرى مثلما هو المعنى بالعربية، حاملا كذلك الفعل العبري كل من المعاني التالية: حل الألغاز والمشاكل، والتَّسوية بين خصمين، والصُّلح، والالتزام بالوعود، وما اتفق عليه. وجميع هذه المعاني لها علاقة بعملية الترجمة وفهم الكلام والنصوص من أجل تعسيرها وتبسيطها وتوضيحها. ولا ترد أيضا كلمة "ترجمة" ولا فعلها في القرآن الكريم الذي، مثلما يحدث بالتوراة، يستعمل كلمة التأويل للإثارة إلى مقصود الكلام أو حقيقته، وأيضا إلى عبارة الرؤيا. وذلك في سبعة عشر موضعا. ولا يظهر كلمة "تقسير" إلا في موطن واحدٍ فقط في الذكر الحكيم، وهو

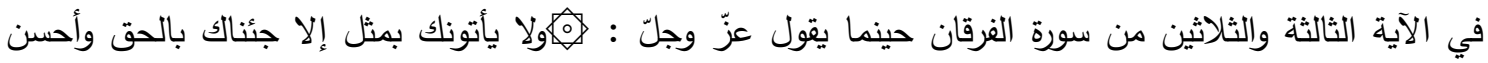
تفيرالهي

وبناء على ما قد قيل،فإننا نرى أن الترجمة في مفهومها السامي والعربي والإسلامي، ليست خيانة مثل ما يحدث في الحضارة الأوروبية، وفي البحوث عنها بل هي دراسة وتفسير بأوجز وأبلغ طريقة عما ورد في لغة مختلفة عن اللغة المستخدمة في تلك الدراسة وذلك التفسير • وبسبب ذلك لا يرمز مفهوم الترجمة في العربية وفي اللغات السامية الأخرى إلى الخيانة بل إلى الأمانة في الدقة وملاءمة اختيار ما يقابل الكلام الأصلي في شرحه بلغة ما أو في النقل إلى لغة أخرى. ولأجل ذلك فإن المترجم في اللغة العربية، وفي سائر اللغات السامية، إنسان أمين يقوم بعمل جائز وممكن، يقدر تقديرا حسنا يحتمل فيه الخطأ والعجز والتشويه، بخلاف النظرة الملقاة عليه في اللغات الغربية التي تصوره على أنه إنسان غادر يقوم بعمل شبه ممتنع يكاد يكون مستحيلا ويقدر تقديرا سيئا في البداية (وفي أغلب الأحوال أيضا في النهاية)، يحتمل فيه الصواب والقدرة والأمانة.

ولكن هناك نوع من الخيانة عند نفر من المترجمين ليس كامنا في الترجمة بذاتها، بل في المنطلق الذي

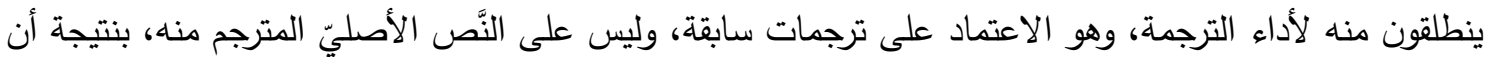

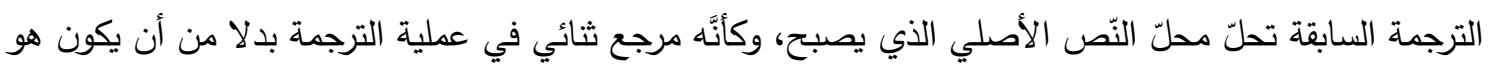

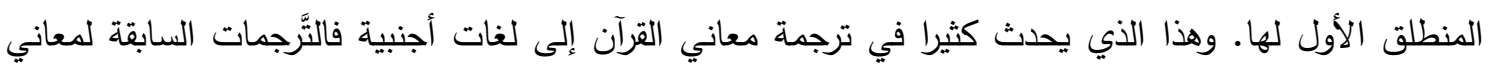

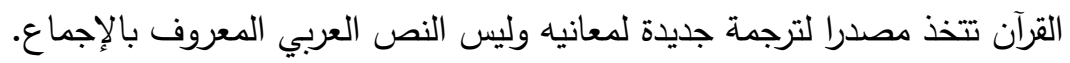

وهذا الذي يحدث كثيرًا في ترجمة معاني القرآن إلى لغات أجنبية، فالتَّرجمات السَّابقة لمعاني القرآن تتخذ مصدرا لترجمة جديدة لمعانيه، وليس النص العربي المعروف بالإجماع. وهو الأمر الذي يجعل كثيرا من الترجمات الجديدة لمعاني القرآن تعيد الأخطاء والانحرافات الواردة في الترجمات القديمة، ويسبب أخطاء أخرى مستحدثة آتية 
من الامتتاع من الرجوع إلى النص الأصلي للقرآن بالعربية ووعيه بهذه اللغة قبل كل شيء. وإذا كان هناك لزوم في الرجوع إلى أصل القرآن بالعربية، فهناك ضرورة في الرجوع إلى التفاسير المكتوبة في شأنه من أجل التزود بأدوات دلالية ونحوية تسهل عملية ترجمة معاني الذكر الحكيم، وليس فقط بغية فهم القرآن على الوجه السليم الذي نزل به على محمد -صلوات الله عليه وسلم- وتلقاه معاصروه من قابل به ومنكر له. وهذه الطريقة في أعمال تفاسير القرآن في ترجمة معانيه غير معهودة وغير مألوفة في معظم الأحيان، رغم الإدعاء بذلك.

وعلى هذا فإنَّه صح ما قاله الأستاذ المرحوم إدوارد سعيد بهذا الصدد متحدثا عن مؤلفات المستشرقين

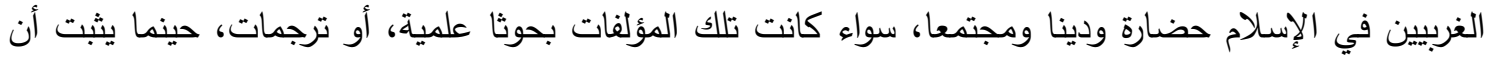

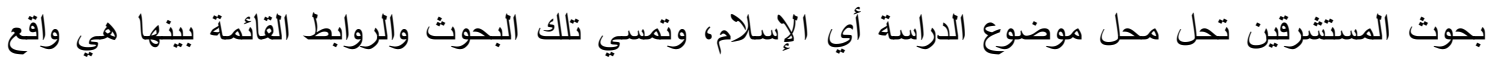
الإسلام والمسلمين وليست مجرد دراسات وتحليلات عما هو الواقع عند الإسلام والمسلمين. وتصير الفكرة المرسومة

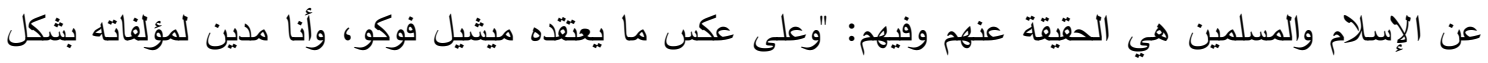

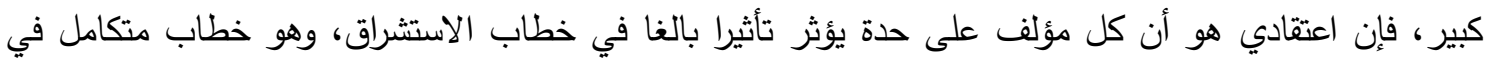
هيكله، متكون من مؤلفات جماعية وفردية" (إدوراد سعيد: الاستشراق: ص 44).

وتدل كلمة ترجمة بمقتى حروفها على العمليات التي لا بد منها في القيام بالترجمة وهي :

$$
\text { أ) فهم الكلام المطروح للترجمة }
$$

ب) إدراك المقصود به أي دراسته في جميع أبعاده ت) نقل معنى الكلام بالألفاظ والأسلوب المناسبين في أدب ونحو اللغة المترجم إليها ث) رعاية ثقافة متلقي الكلام المُترجم في جميع المستويات الثقافية المتواجدة وقت القيام بالترجمة في تلك

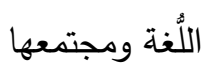

وبجملة كل هذه العمليات تتم الترجمة في أحسن أداء، ولا غَرْوَ إذن حينما وصف عبد الله ابن مسعود صاحب النبي -صلى الله عليه وسلم-عبد الله ابن عباس بأنه "ترجمان القرآن"، أي مُفِيّره وموضحه، وذلك دون الخروج من اللغة العربية، فإذا كان الأمر يخص النقل من لغة إلى أخرى، فإن ذلك التقسير يزداد أهمية وخطورة. ومثلما يشترط تقسير القرآن شروطا لمن يرغب في القيام به، فكذلك تشترط ترجمة القرآن لمن أرادها شروطا خاصة. وفي هذا الصَّدد لا بُدَّ من الإشارة إلى ما قاله الجاحظ عن المعارف والمهارات المطلوبة عند المترجم من الناحية اللغوية، ومن ناحية السياق، فقال متحدًٍِّا عن ترجمة أبيات الثعر العربي إلى لغات أخرى (لحيوان: ج 1 ص 76): "وكيف يقدر على أدائها وتسليم معانيها والإخبار عنها على حقها وصدقها إلا أن يكون في العلم بمعانيها واستعمال تصاريف ألفاظها وتأويلات مخارجها مثل مؤلف الكتاب وواضعه". 
وكل هذه المعارف والمهارات هي أيضا المطلوبة في القيام بأية ترجمة وبالخصوص ترجمة آيات القرآن.ولقد جعل الجاحظ في مقولته السابقة الترجمان في مكان مؤلف الكتاب وواضعه. ويطابق هذا الوصف التف الفكرة السائدة حاليا في الدراسات حول الترجمة، التي تتظر إلى المترجم على أنه مؤلف ثان للكتاب المترجم منه في للغة فئه المترجم إليها.

وبالطَّبع فإنَّه من غير الممكن لا بل من المستحيل تطبيق هذه الفكرة على القرآن؛ لأنَّ مؤلفه وواضعه هو الله نفسه، وهو أمر فيه علاقة مباشرة بالبعد الإعجازي والمجازي للقرآن، وهيكليته اللغوية والأدبية. لكن من الممكن في مكان ومن الواجب نقل معاني النصوص القرآنية بمراعاة غرض المؤلف الإلهي للقرآن حسبما فهمه من تلقى الذكر الحكيم انطلاقا من رسول الله -صلى الله عليه وسلم- إلى آخر من بلغه الكتاب المنزل من ذوي العقل والإيمان،وبالأخص الأئمة المفسرين لكلام الله. ومن أجل هذا فلا بد لمترجم معاني القرآن من العودة إلى ما قد ألفه من اهتم بفهم وتفهيم مضمون القرآن ممن برع في ذلك وقدم علما نافعا فيه. ويسرد الجاحظ في قوله السابق ثلاث معارف لا بد منها للقيام بالترجمة على ما يرام، ولو في النية، وفي الخطة الأولى مع تحضير النفس والأمور من أجلها:

$$
\text { أ) أ فهم معاني الألفاظ أي دلالاتها. }
$$

ب) معرفة تصاريف الألفاظ أي معانيها حسب تركيبها في الجملة ووضعها من الإعراب ومكانتها في

$$
\text { السياق. }
$$

$$
\text { ت) إدراك مرامي الكلام، وهو ما يسميه الجاحظ تأويلات مخارجها. }
$$

وهذه المعارف الثلاث تحول المترجم إلى مؤلف للنص، وتجعله واضعا لذلك الكتاب في اللغة المترجم إليها، وتحمله مسؤولية القيام بترجمة وافية والقطع على نفسه ببذل الجها والتماس والوفاء فيها.

وهذه المعارف التي ذكرناها سابقا في خصوصية المترجم تماثل مهارتين من المهارات الأربع التي أثرنا إليها في فقرة سابقة،وهي فهم الكلام المطروح للترجمة وإدراك المقصود منه أي دراسته في جميع أبعاده. وهما مهارتان على اتصال لصيق بالنص المترجم هنه، ولقد أضفنا مهارتين أخربين لهما صلة بالنص المترجم إليه وهما:نقل معنى الكلام بالألفاظ والأسلوب المناسبين في أدب ونحو اللغة المترجم إليها، ورعاية ثقافة متلقي الكلام المترجم في جميع المستويات المتواجدة في تلك الثقافة.

ولا تتوفر هذه المعارف الثلاث المشار إليها من طرف الجاحظ ولا الأبع مهارات المذكورة عندنا إلا باكتسابها بفضل طول المطالعة والاستماع إلى الكلام الناتج في اللغة المترجم منها، وكذلك في اللغة المترجم إليها،على الرغم من أن الجاحظ في الجملة المذكورة عنه لا يتحدث إلا عن المعارف المطلوبة في اللغة المترجم عنها، وليس في اللغة المترجم إليها. ولكن هذه الحقيقة لم تغب عن الجاحظ إذ يقول لاحقًا إنَّ البلاغة يجب أن يمتلكها المترجم في اللُّتين كلتيهما اللَّتين يترجم بينهما، وذلك على الرغم من أن التساوي في البلاغة في لغتين يكاد 
يكون مستحيلا (كتاب الحيوان: ص 78): "ولو كان الحاذق بلسان اليونانيين يرمي إلى الحاذق بلسان العربية، ثم كان العربي مقصرا عن مقدار بلاغة اليوناني، لم يجد المعنى والناقل التقصير ، ولم يجد اليوناني الذي لم يرض بمقدار بلاغته في لسان العربية بدا من الاغتفار والتجاوز".

وإذا كان التساوي في معرفة لغتين عند الثخص الواحد أمرًا يتعذر تحصيله، فالأحسن من ناحية الترجمة أن يكون الترجيح للغة المترجم إليها فإن الترجمة تطلب جها أكبر ومهارة أفضل في اللغة المترجم إليها. أما اللغة المترجم منها فالملتمس فيها هو الفهم الصحيح لمعاني النص المترجم منه دون الكفاءة في محاكاة لغته. وهذه الحقيقة تنطبق على القرآن؛ لأن خصائص القرآن، بما فيها الإعجاز، تستدعي وعيها ومراعاتها في قراءة الكتاب العزيز وتدبره لاكتساب القدرة على ترجمة معانيه إلى لغة أخرى على ما يرام. ومع استحالة ترجمة إعجار القرآن، فإن هناك حاجة ملحة في الإيماء إليه في الترجمة بإفضاء أحسن صورة لغوية ولفظية على ترجمة معاني القرآن، وذلك ممكن باحتذاء الأسلوب الأفضل تقديرا لغة وأدبا في اللغة المترجم إليها. وهذا هو الذي اكتشفناه في ترجمة بعض الآيات القرآنية عند مستشرق إسباني عاش بين نهاية القرن التاسع عشر والثلث الأول من القرن العشرين واسمه ماكسيم يليانو ألاركون (1880-1933).

فهو يترجم الآيات التالية بأسلوب لا مثيل له في الترجمات الأسبانية قديمة كانت أو حديثة، إلى درجة أنه يمكننا القول بأنه لو سنحت للسيد ألاركون ترجمة جميع القرآن لكانت أوفى ترجمة لمعاني القرآن باللغة الإسبانية وأجملها؛ لأن أسلوبه بالإسبانية سلس، ويستسيغه القارئ الإسباني استساغة تامة، وذلك فضل كبير لترجمة السيد ألاركون عن الآيات القرآنية، فإنه نقل معاني القرآن في قالب يماثل أعلى أسلوب في التعبير باللغة الإسبانية، وهذا يقابل الأسلوب الرفيع في للغة العربية للقرآن وإن لم يصل إلى إعجاز القرآن إعجاز واقع في العربية، فالإعجاز للقرآن بالعربية لا وجود له في لغة أخرى في العالم كله وفي التاريخ برمته. ولكن ترجمة ألاركون للآيات القرآنية توحي في القارئ الأسباني لتلك الترجمة فكرة عما يقارب شعور القارئ والسامع العربيين للقرآن فيما يتعلق بإعجاز القرآن لغويا، وذلك فضلا عن الحكمة الواردة في كلام الله المنزل.

وهنا أمثلة ستة من ترجمة ماكسيم يليانو ألاركون لبعض الآيات القرآنية تتحلى بأسلوب أدبي رائع باللُّة

الإسبانية: (n)

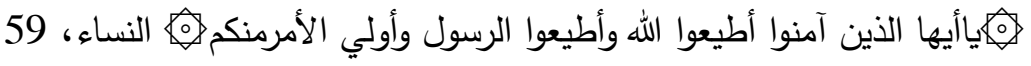

"Creyentes. Obedeced al Señor, al Profeta y a aquellos de vosotros que ejerzan la autoridad" (azora de las mujeres, IV, 59)

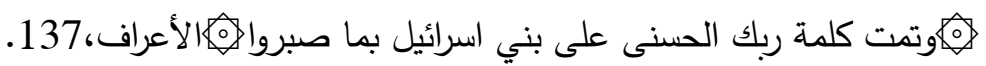


"Tuvieron cumplimiento las bellas promesas hechas por tu Señor a los israelitas, a causa de la perseverancia de que dieron muestras" (azora de los lugares elevados, VII, 137).

$$
\text { هأصرف عن آياتي الذين يتكبرون في الأرض بغير حق ه\&الأعراف، } 146 .
$$

"Apartaré de mis enseñanzas a aquellos que, en la tierra, se enorgullecen sin razón" (azora de los lugares elevados, VII: 146).

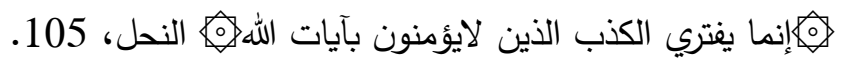

"Incurren a la mentira los que no creen en los prodigios del Señor" (azora de las abejas, XVI:105).

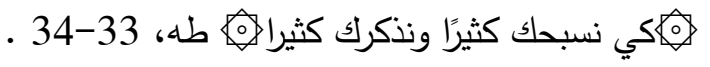

"Para que celebremos sin cesar tus alabanzas y pensemos en ti constantemente" (azora Ta Ha, XX: 33-34).

$$
\text { . } 10 \text { ، } 10 \text { إنما يوفى الصابرون أجرهم بغيرحساب الزمر }
$$

"Solamente los que sufren con paciencia recibirán su recompensa sin tasa" (azora de los grupos, XXXIX, 10).

$$
\begin{aligned}
& \text { وإيحاء شعور مماثل قدر الإمكان، للشعور الذي يحس به قارئ أو سامع النص الأصلي عند قارئ أو } \\
& \text { سامع النص المترجم إليه هو غرض كل ترجمة وافية (بجانب نقل مضمون النص الأصلي) حسب مفهوم أوجين } \\
& \text { نيدا الباحث الثهير في أمور الترجمة وبخاصة في ترجمة الكتاب المقد إلى مختلف لغات العالم، الذي يقول } \\
& \text { (الترجمة في تنظيرها وتطبيقها : 1986، ص 15): "اليوم، بخلاف ما كان يحدث من قبل، ليس المهم في الترجمة } \\
& \text { صياغة المضمون، بل إثارة رد فعل عند متلقي الترجمة، فإن الأهم هو أن يشعر متلقي الترجمة أمام الترجمة وقدر } \\
& \text { الإمكان بنفس المشاعر التي شعر بها متلقو النص الأصلي الأوائل". وهذا الهذف في الترجمة الوافية لاى أوجين } \\
& \text { نيدا هو الذي دللنا عليه حينما قلنا إنه من العمليات التي لا غنى عنها في إنجاز ترجمة وافية،عملية نقل الكلام }
\end{aligned}
$$


بالألفاظ والأسلوب المناسبين في أدب ونحو اللغة المترجم إليها، وعملية رعاية ثقافة متلقي الكلام المترجم في جميع المستويات المتواجدة لتلك الثقافة.

وللقيام بترجمة وافية عن معاني القرآن إلى لغة أخرى ليس إسلام المترجم شرطا ضروريا لذلك؛ لأن الترجمة علم وفن، وعلى ذلك هي خاضعة لسنن الكون الجاري المفعول على البشر أجمع، بغض النظر عن العقيدة، ومن استوعب أسباب العلم والفن في عملية الترجمة؛ فإنه سيؤدي ترجمة لمعاني القرآن، لا محالة، بوفاء ولو بالتفاوت اللازم لكل عمل بشري، وكم هو أكثر في ترجمة معاني القرآن.

وهذا الذي لاحظنا فيما يخص الترجمات الإسبانية للقرآن، فإن هناك عدة ترجمات لمعاني القرآن إلى اللغة

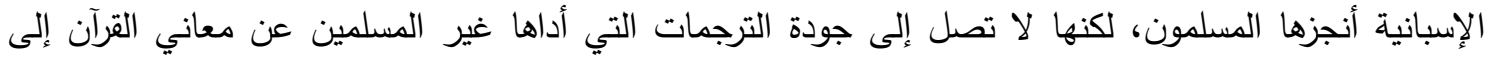
اللغة الإسبانية، سواء كان في اختيار المصطلحات المناسبة أو في أسلوب الإملاء المختار لنقل الآيات القرآنية إلى لى لهيك للغة الأسبانية، بالرغم من أن أسلوب الترجمات الأسبانية لمعاني القرآن التي عملها المسلمون لا تخلو من اهتمام أكبر لوضع أسلوب سائخ للقارئ الإسباني أكثر مما هو ملحوظ في الترجمات الأسبانية التي تم بأيدي المستشرقين، وإن كانت هذه الترجمات الاسبانية للمستشرقين أكثر جودة أدبية وترجمتية من الترجمات التي هي من نتاج المسلمين.

وذلك أمر يتطلب الالتفات إليه ودراسته وتحليله بغية الاستفادة من استتتاجات ذلك البحث واستخدامها في الإقبال على ترجمات أفضل، إسبانية وغير إسبانية، سواء كان الأمر من جانب الاصطلاح أو من جانب الأسلوب الأدبي.

ومن أجل الحصول على ترجمة وافية للنصوص التي تتصف بمضامين غير مقعدة لغة وموضوعا، فإن معرفة كافية باللغتين عامة وبلغة النص الذي يقام بترجمته خاصة كفيلة بالنجاح. أما النصوص المتخصصة فهي على جانب من إجادة لغة النص ولغة الترجمة، فالإلمام الكافي بالموضوع ضمان للفوز بها. ويأتي هذا الإلمام بتوثيق الموضوع. وفيما يتعلَّق بترجمة معاني القرآن، فإنَّ التفاسير هي المصدر الأول للقيام بذلك التوثيق، وعلى ذلك فقد شددنا على أهميتها للوصول إلى هذا الغرض. وذلك على خلاف ما يؤكد الجاحظ (لحيوان: ج1، ص76) أنه "لا بد للترجمان من أن يكون بيانه في نفس الترجمة في وزن علمه في نفس المعرفة. وينبغى أن يكون أعلم الناس باللغة المنقولة والمنقول إليها حتى يكون فيهما سواء وغاية".

وشرط الجاحظ على الترجمان أن يكون خبيرا متخصصا في الموضوع الذي يترجمه، قبل أن يكون خبيرا في آليات الترجمة، هوالفكرة الرائجة بين من يتطرق إلى أمور الترجمة، وهناك جدال قديم محتدم حول من هو الأفضل هل المتخصص الذي يجيد اللغات الأجنبية والترجمة بين لغته الأم وهذه اللغات الأخرى، أو المترجم الذي يتخصص في ترجمة علم أو موضوع بفضل اكتسابه الخبرة الكافية لذلك. 
ورأينا النابع عن تجربة الترجمة ودراستها أن المترجم المتخصص هو أفضل من المتخصص الذي يعرف عدة لغات ويترجم بينها، فإن الترجمة علم وفن يحتاجان إلى اكتساب وتدريب، ومن يحصل عليهما هو أكثر كفاءة في نقل المعاني من لغة إلى أخرى بشرط التوثيق الملائم في الموضوع الذي يترجمه. وتجري هذه الحقيقة على ترجمة معاني القرآن مثلما تجرى على نصوص أخرى دينية أو غير دينية، فمن يعرف صعوبات الترجمة وحلها أولى بالإقدام على ترجمة تحتمل الفوز والصواب النسبيين كما هو الثأن في كل ترجمة، وبالأحرى في ترجمة الكتب الدينية أو الفكرية وفوق كلها ومهيمنا عليها، القرآن الكريم.

ومن أهم القضايا في الترجمة وأيضا في الإنتاج الفكري، هو الرصيد الثقافي الذي يجب اكتنازه على مدى أنى الحياة دون انقطاع. وهذه المسألة جوهرية في تدريب وتدرب المترجمين. وعلى المترجمين أنفسهم إنشاء "مكتبة" ذهنية في الذاكرة والوجدان للرجوع إليها كلما دعت الضرورة وقت شروعهم في الترجمة أو في تأليف أي نص. تصن.

وفيما مضى من الزمان، كانت هذه المكتبة الذهنية مشتركة بين معظم المثقين في حضارة ما بغض مذا النظر عن هوية هذه الأخيرة.وقد استمرت هذه الحالة إلى ظهور ما سمي بفكرة ما بعد الحداثة في الحضارة

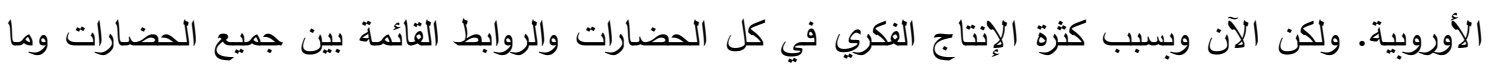
كتب فيها من أدب وأفكار قد انحلت الشراكة في تلك المكتبة الذهنية التي كانت تشمل جميع الكتب التي كانت ولت التيط معرفتها واجبة على كل من كان يرغب في التثقف والتثقيف. ولكن وإن لم يبق من الممكن المشاركة في جميع

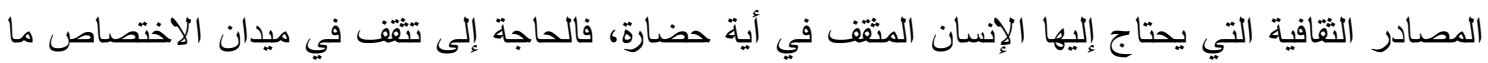
زال قائما وملحا للمثقف العام وللمتخصص في علم بما في ذلك هؤلاء المترجمين، وعلى وجه الخصوص مترجم

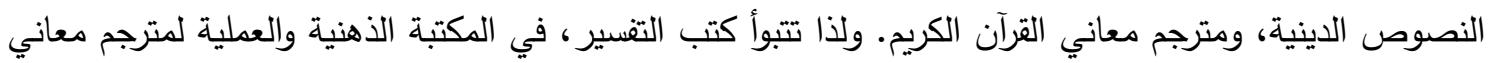

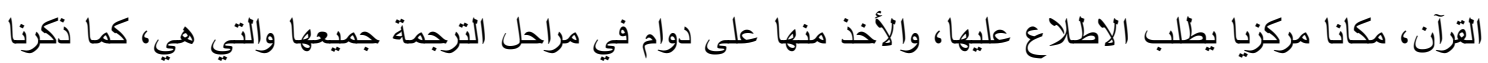
سابقا، الآتية:

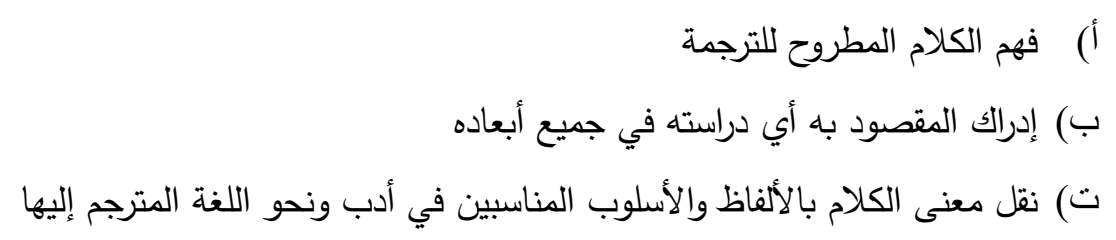
ث) رعاية ثقافة متلقي الكلام المترجم في جميع المستويات الثقافية المتواجدة وقت القيام بالترجمة في تلك اللغة ومجتمعها التفسير والتأويل: دعامتا ترجمة معاني القرآن علينا التتبيه هنا إلى أن تفسير القرآن هو المطلوب الإسناد إليه في ترجمة معانيه في الدرجة الأولى، ولا يأتي التأويل (أي المقصود بالكلام) إلا في الارجة الثانية بالرغم من أنه ضروري اعتباره بسبب أنه لا يتم معنى الأية أو بعضها أو جملة منها إلا بالإلمام بما رمت إليه من معان. 
ونعني بتفسير القرآن -هنا- ما عرفه أبو حيان في البحر المحيط (البحر المحيط: 2010، ج 1 ص 121): "علم يبحث عن كيفية النطق بألفاظ القرآن ومدلولاتها وأحكامها الإفرادية والتركيبية ومعانيها التي تحمل عليها حالة التركيب وتتمات لذلك". وذلك هو جوهر التفسير الذي نومئ إليه في هذا البحث، والذي يسعى للإيضاح الذي يعقب به أبو حيان الأندلسي تعريفه السابق (البحر المحيط. 2010,ج 1 ص 121): "فقولنا علم هو جنس يشمل سائر العلوم، وقولنا يبحث فيه عن كيفية النطق بألفاظ القرآن، هذا هو علم القراءات وقولنا ومدلولاتها، أي مدلولات الألفاظ وهذا هو علم اللغة الذي يحتاج إليه في هذا العلم [أي علم التفسير]، وقولنا وأحكامها الإفرادية والتركيبية هذا يشمل علم التصريف، وعلم الإعراب، وعلم البيان، وعلم البديع، ومعانيها التي تحمل عليها حالة التركيب شمل بقوله التي تحمل عليها ما لا دلالة عليه بالحقيقة وما دلالته عليه بالمجاز ، فإن التركيب قد يقتضي بظاهره شيئا ويصد عن الحمل على الظاهر صاد فيحتاج لأجل ذلك أن يحمل على غير الظاهر وهو المجاز، وقولنا وتتمات لذلك، وهو معرفة النسخ وسبب النزول وقصة توضح بعض ما انبهم في القرآن ونحو ذلك"

أما التأويل فالمراد به -هنا- ما يراه السيوطي في جدع الجوامع أو الجامع الكبير (ج 1، ص 56) أن"التأويل حمل الظاهرعلى المحتمل المرجوح؛ فإن حمل عليه لدليل صحيح، أو لما يظن دليلا في الواقع ففاسد، أو لاشيء فلعب لا تأويل".

وكذلك يكمننا فهم التفسير والتأويل اللذين يعينان على الترجمة الوافية بالتحديد الذي حدده لهما أبو طالب

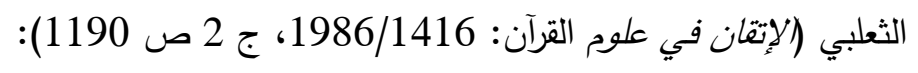

"التفسير بيان وضع اللفظ، إما حقيقة أو مجازا كتفير الصراط بالطريق والصيب بالمطر ، والتأويل تفسير باطن اللفظ، مأخوذ من الأول وهو الرجوع لعاقبة الأمر، والتأويل إخبار عن حقيقة المراد؛ لأن اللفظ يكثف عن المراد والكاشف دليل .. [..] وقواطع الأدلة تقتضي بيان المراد منه على خلاف وضع اللفظ في اللغة". وللترجمة حاجة إلى التفسير والتأويل في جميع النصوص، وبخاصة في النصوص البالغة الأهمية مثلما هو الثأن في الكتب المقدسة ومن ضمنها القرآن، وذلك علما بأن ترجمة القرآن هي ترجمة معانيه، وليس ترجمة نظامه التعبيري، فإنه مستحيل في القرآن بالأخص، وفي النصوص الدينية الكبرى الأخرى عامة، ولو لم تشترك مع القرآن في الإعجاز الوارد فيه. وفي الإمكان تعميم حكم استحالة ترجمة النظام التعبيري على جميع النصوص الأدبية ذات قيمة فنية رفيعة مع إدراك الفوارق بينها وبين القرآن من جهة إعجاز الذكر الحكيم. وكذلك لا يحل استخدام تقسير القرآن بالعربية لا في التعبد به ولا في اعتباره الكلام المنزل من الله، فكذلك الترجمة لا تحل مكان القرآن، لا في التعبد بها، ولا في اعتبارها الوحي المنزل على النبي -صلى الله عليه وسلم-لأنهما أي التفسير والترجمة وسيلتان لفهم القرآن من أجل العمل به فكلاهما جائز على هذا الشرط: 
"ومن -هنا- قال القفال [ت365هـ] من أصحابنا: عندي أنه لا يقدر أحد أن يأتي بالقرآن بالفارسية، قيل له: إذن لا يقدر أحد أن يفسر القرآن، قال: ليس كذلك لأن هناك يجوز أن تأتي ببعض مراد الله ويعز عن البعض [وكذلك في الترجمة] أما إذا أراد أن يقرأه بالفارسية، فلا يمكن أن تأتي بجميع مراد الله، فإن الترجمة [يمعنى حل الترجمة محل النص الأصيل للقرآن] إبدال لفظة بلفظة تقوم مقامها، وذلك غير ممكن بخلاف التفسير [والترجمة لمعاني القرآن]" (لكبرهان في علوم القرآن: ج 1 ص 465).

وفيما هو الترجمة بعينها وقبل القيام بوضع الألفاظ والعبارات الأجنبية مكان الألفاظ والعبارات الأصلية، لا بد من معرفة كاملة لمعنى تلك الألفاظ والعبارات. وهذه العملية الأولى في الترجمة هي ما يقابل التفسير في فهم النصوص دينية كانت أو أدبية أو أي نوع آخر من النصوص ذات أبعاد متعددة.

والخطوة الثانية في عملية الترجمة هي فهم معاني الألفاظ أو العبارات في سياق الخطاب، من أجل التأكد من الهدف الذي يرمي إليه اللَّظظ أو تلك العبارة. وهنا يدخل التأويل أي كثف مقصد الكلام فضلا عن دلالة الكلام في ألفاظه وتركبيه.

والجمع بين الخطوة الأولى والثانية في عملية الترجمة بعامة، وفي ترجمة معاني القرآن بخاصة ما ضبطه

$$
\text { الإمام الزركثي في وصفه لتفسير القرآن ومضامينه (البرهان في علوم القرآن: ج } 1 \text { ص 15): }
$$

"ومعلوم أن تفسيره [أي تفسير القرآن] يكون من قبيل بسط الألفاظ الوجيزة وكثف معانيها وبعضه من قبيل ترجيح بعض الاحتمالات على بعض لبلاغته ولطف معانيه، ولهذا لا يستغنى عن قانون عام يعول في تفسيره عليه، ويرجع في تقنيره إليه من خلال:

$$
\begin{aligned}
& \text { أ) معرفة مفرادات ألفاظه }
\end{aligned}
$$

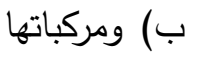

$$
\begin{aligned}
& \text { ت) وسياقها } \\
& \text { ث) وظاهره } \\
& \text { ج) وباطنه }
\end{aligned}
$$

وغير ذلك مما لا يدخل تحت الوهم، ويدق عنه الفهر".

وحينما اتضح مقصود الكلام في لفظه وفي وضعهيتم تبديله بما يقابله لفظا ومرادا في اللغة الأجنبية. وذلك في جميع حالات الترجمة أو على الأقل في جميع حالات الترجمة الوافية لغرضها الأمينة لموضوعها.

وفي النصوص العادية يأتي التفسير من الرصيد اللغوي للمترجم، ويجيء التأويل من خبرة المترجم في طريقة استعمال الكلام الخاص بلغة ما سواء أكانت اللغة المترجم منها أو المترجم إليها. وكلا الأمرين يقتضي قراءة واسعة لمختلف النصوص الموجودة في اللغات الداخلة في عملية الترجمة. 
وتقع هذه الحالة في ترجمة معاني القرآن إلا أن هناك مجموعة هائلة من التفاسير للنص القرآني التي تحتمل كذلك التأويل في بعض الآيات أو مجموعة منها على ما هو واقع بالمشكل والمتشابه في القرآن. والحاجة إلى فهم القرآن بفضل التفسير موجودة عند العرب حتى في أيام الوحي، وهي الآن أثد فما بالكم لمن يرغب في ترجمة معاني القرآن لكي يقدم ترجمة وافية تلبي حوائج المعرفة لدى من يهتم بالقرآن من المسلمين وغير مسلمين وهو ليس بعربي. وهي حاجة أشار إليها المفسرون أنفسه، فيقول في ذلك الإمام الرزكشي (لإهان في علوم القرآن: ج 1 ص 14-15):

"إن القرآن إنما أنزل بلسان عربي مبين في زمن أفصح العرب وكانوا يعلمون ظواهره وأحكامه، أما دقائق باطنه فإنما كان يظهر لهم بعد البحث والنظر . [...] ولم ينقل إلينا عنهم [عن الصحابة] تفسير القرآن وتأويله بجملته، فنحن نحتاج إلى ما كانوا يحتاجون إليه وزيادة على ما لم يكونوا محتاجين إليه من أحكام الظواهر لقصورنا عن مدارك أحكام للغة بغير تعلم فنحن أشد الناس احتياجا إلى التفسير". وكذلك من ينوي ترجمة معاني القرآن في كلِّ زمن.

وكثيرا ما يحدث أن ما يتم تقديمه على أنه ترجمة فهو في الحقيقة تأويل فاسد، أو لعب بالمعاني للنص المترجم منه، لكن الترجمة هي التفسير بلغة أخرى وليس التأويل دون دليل أو قرينة، فإن كان كذا فهو فاسد أو لها لعب كما يقول السيوطي والأمر هو ذاته في الترجمة التي تقبل التأويل في حالتين وحيدتين: في انغلاق المعنى في اللغة المترجم إليها إذا كانت العبارة المترجمة في اللغة المترجم إليها غير مفهومة لبعد تباين التصور عند اللغتين الموصولة عبر الترجمة أو لعدم لياقة ترجمة العبارة في اللغة المترجم إليها على الثكل الوارد في اللغة المترجم منها. وتكتمل الترجمة التي تفي بغرضها والتي ليست حرفية ولا تفسيرية بل ترجمة مفيدة بإنشاء نص جديد باللغة المترجم إليها مع استيعاب جميع جوانب النص الأصلي في التعبير والدلالة والبلاغة والبديع على قدر الإمكانهوذلك برعاية اختلاف أساليب التعبير في اللغتين.

والأساليب متفاوتة النجاح في نقل النص الأصلي إلى النص المنشأ في اللغة الثانية كما هي متفاوتة القدرة المتواجدة في المترجم في إعمال هذه الأساليب في اللغة المترجم إليها. والتفاوت في القدرة على القيام بترجمة وافية لمعاني القرآن خاصة ولنصوص غيره عامة، هو أمر آت على حساب كفاءة المترجم مثلما يحدث مع المفسر بعينه:

"وفي هذا [أي القدرة على تقسير القرآن والاستنباط منه] تتفاوت الأذهان وتتسابق في النظر مسابقة الزّرهان. فمن سابق بفهمه وراشق كبد الرَِّيَّة بسهمه وآخر رمى بأشوى وخبط في النظر خبط عشوا، كما قيل: وأين

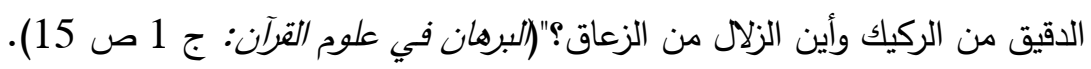


وعلى ذلك من الفائدة الإتيان بملاحظة الأستاذ محمد حسين الذهبي حينما يتحدث عن الترجمة الحرفية، والتي من الممكن تطبيقها في الترجمة الوافية فيما يتعلق بنقل المعنى المرمي إليه قبل كل شيء بأسلوب مستساغ لاى قارئ أو سامع اللغة المترجم إليها (لتنسير والدفسرون: 2005، ص 28):

"ومثل هذا التعبير في اللغة المترجم إليها ربما كان لا يؤدي المعنى الذي قصده القرآن، بل وقد يستنكر صاحب تلك اللغة هذا الوضع الذي ينهى عنه القرآن، ويقول في نفسه: إنه لا يوجد عاقل يفعل بنفسه هذا الفعل الذي نهى عنه القرآن [...]؛ لأنه مثير للضحك على فاعله والسخرية منه، ولا يدور بخلد صاحب هذه اللغة المعنى الذي أراده القرآن، وقصده من وراء هذا التشبيه البليغ [...] أما إذا أراد أن يترجم هذه الجملة ترجمة تفسيرية [أي وافية في صيغة مقبولة]، فإنه يأتي بالنهي عن التبذير والتقتير مصورين بصورة شنيعة، ينفر منها الإنسان، حسبما يناسب أسلوب تلك اللغة المترجم إليها ويناسب إلف من يتكلم بها".

وإذا شملت الترجمة معنى التقسير في لغة أخرى وبعبارات أخرى فالعكس صحيح. ونرى أن التفسير يضمن كذلك الترجمة. وعلى هذا الأساس فإن ترجمة معاني القرآن قد نظر علماء الإسلام إليها على أنها نوع من التفسير، وهي جائزة لضرورة العمل به كما يقول الإمام الثاطبي:"فأما في الوجه الثاني [أي إمكانية الإخبار في لغة معينة عما جاء في لغة أخرى مثلما هي الحال في ترجمة معاني القرآن] فهو ممكن ومن جهته صح تفسير القرآن وبيان معناه للعامة ومن ليس له فهم يقوى على تحصيل معانيه، وكان ذلك جائزًا باتقاق أهل الإسلام وهذا الاتفاق حجة في صحة الترجمة على المعنى الأصلي" (الثاطبي: الموافقات في أصول الثريعة: 1996/1416، ج 1 ص 378)

وإذا كانت ترجمة النصوص العادية تقتضي فهم الكلام وإدراك قصده وشرحه لمن لم يفهمه في قالبه الأول، فبالأحرى يقتضي ذلك تفسير النصوص المتخصصة، ومن ضمنها النصوص الدينية وفوقها كلها نصوص القرآن الكريم الذي هو الوحي الأخير في الرسالات السماوية.

وفي عملية ترجمة معاني القرآن يلتقي هذان الوجهان (الفهم والثرح) في الترجمة والتفسير، ولفهم الآيات القرآنية وإدراك مقصدها، فإنَّ هناك حاجة مُلحَّة ضرورة معرفة خصوصية كل آية وبعض الآية وجملة من الآيات حسبما نبه إلى ذلك المفسرون، فإن لعربية القرآن خصوصية تتطلب رعايتها في وعيها وشرحها وترجمتها. ومجمل التفاسير يساعد على ذلك ويسهله فإذا كانت على الأصوليين والفقهاء التمكن من اللغة العربية حسب ورودها واستخدامها في القرآن والأحاديث النبوية وأخبار الصحابة والتابعين وأقوال العلماء فالضرورة أشد وألح لمترجمي معاني القرآن ففي الحقيقة هم يقومون بتفسير جديد لنص القرآن في ظروف جديدة تستلزم الأمانة واحترام الأصل. وذلك، أي أن ترجمة معاني القرآن نوع من التفسير، أمر قد فطن له من قبل علماء الإسلام كما ذكرنا آنفًا. وترجمة معاني القرآن تفسير خاص يغلب عليه بعض الميول والخصائص، على غرار ما هو وارد في أنواع أخرى للتفسير 
التي تهيمن عليها جوانب مختلفة مثل القصص، أو علم البيان، أو اللفظ الغريب، أو الأحكام، أو الإعراب، أو النحو وما إلى ذلك.

وهناك من الخبراء المسلمين من ذهب إلى ما هو أبعد مما قلناه إلى حد الآن، ويرى أن الترجمة نوع من التفسير الواجب على الأمة الإسلامية وعلى وجه الخصوص على العرب؛ لأنَّ هناك الكثير من المسلمين لا ينطقون بالعربية ولا يفهمونها وأخطر من ذلك أن الأمم والأفراد غير المسلمين لهم الحق في الإطلاع، ولو بالمعنى، على ما جاء باه وحي القرآن:

"ليس القرآن للعرب دون الناس بل للناس كافة. وإذا ما جرت محاولة لترجمته إلى لغات أخرى فسيظل القرآن كتابا مغلقا للأمم الأخرى، مفتوحا للعرب فقط. وحتى للعرب فإنه نظرا لاختلاف لهجاتهم والتغير الذي طرأ على اللغة العربية المستخدمة في التخاطب والكتابة طوال الأربعة عشر قرنا الماضية، ليس في وسع العرب أن يفهموا لغة القرآن بوضوح [وهو يشير إلى غير المتخصص في علوم القرآن والثريعة وغير المثقف ثقافة كافية في العربية]. ولذلك يتساوى المسلمون العرب وغير العرب في قراءة القرآن وفهمه ..

[... لذلك فإذا أيقنا أن القرآن هدى للناس فإن ترجمته (شريطة أن تكون أقرب ما يكون إلى النص العربي) ليس خروجا على النص الأصلي" (عبد الحكيم طبيبي: "تفسير القرآن الكريم وترجمته" في الندوة العالمية حول ترجمات معاني القرآن الكريم، ص 43-44).

وحينما يحول الحديث عن ترجمة القرآن لا بد من أن نضع في الحسبان أن دعوة الإسلام من جهة وقيم القرآن الدينية والفلسفية والحكمية والأدبية من جهة أخرى ليس بحكرٍ على العرب من المسلمين وغير المسلمين، فهناك أدلة شرعية في السنة تدل على جواز الترجمة ووجوبها في بعض الظروف، مثلما كان الأمر بالرسائل التي أرسلها رسول الله إلى كسرى إمبراطور الفرس، وهرقل قيصر الروم، والنجاشي، ملك الحبشة والمقوقس عظيم القبط. فكل وحداة من هذه الرسائل ضمنت ترجمة آيات قرآنية إلى اللُغات المنطوقة لدى هؤلاء الملوك والعظماء والأباطرة. ومن هذا الجانب فإن ترجمة معاني القرآن ليست فقط نوعا من التفسير، بل كذلك من الأعمال التي هي فريضة على الأمة لتقديم هداية الإسلام إلى البشر، وهذه الهداية هي الغرض الثاني في نزول القرآن، فإنَّ الغرض

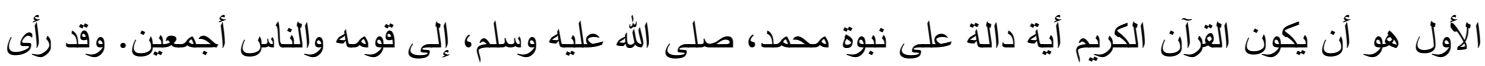
الدكتور محمد حسين الذهبي أن ترجمة معاني القرآن هي جائزة لإطلاع المسلمين غير العرب وأصحاب الديانات والعقائد الأخرى على حقيقة القرآن والإسلام، ولكنا نراها فرضا لنفس الأسباب التي يشير إليها الدكتور الذهبي لإجازة ترجمة القرآن وهذه الأسباب هي:

"وأما الغرض الثاني، وهو كونه [أي القرآن الكريم] هداية للناس إلى ما فيه سعادتهم في الدارين، وذلك باستتباط الأحكام والإرشادات منه، وهذا يرجع بعضه إلى المعاني الأصلية التي يشترك في تفاهمها وأدائها كل الناس، وتقوى عليها جميع اللغات وهذا النوع من المعاني يمكن ترجمته واستفادة الأحكام منه، وبعض آخر من 
الأحكام والإرشادات يستفاد من المعاني الثانوية، ونجد هذا كثيرا في استتباطات الأئمة المجتهدين، وهذه المعاني الثانوية لازمة للقرآن الكريم وبدونها لا يكون قرآنا". (الذهبي: التنسير والدفسرون: 2005، ص 26).

وعلى ذلك فاستخدام التفاسير في ترجمة معاني القرآن يغني الترجمة بهذه المعاني الثانوية التي من المحتمل ضياعها، أو عدم الانتباه إليها في ترجمة قائمة فقط على نقل معاني القرآن الناتجة عن قراءة سطحية للنص القرآني، ولو كانت صائبة من الناحية اللغوية. وقد برهنت التجربة في ترجمة القرآن الكريم بالاستتاد إلى التفاسير أنها فضلا على أنَّها تكون أوفى من غيرها في البعدين اللفظي واللغوي، فإنها آمن -أيضا-من غيرها في إيصال تصور القرآن للأمور ورسمه للمقاصد. وفي هذا الصدد فإن الملحوظ في تحليل ترجمات معاني القرآن أن معظم الأخطاء في الدلالة والقصد، هي نابعة من الاستغناء عن التفاسير وعدم الرجوع إليها للتأكد من مغزى النص القرآني. والأمثلة في ذلك كثيرة وواردة في كل الترجمات الأجنبية لمعاني القرآن، وبالأخصّ التَّرمات الإسبانية، وذلك بالرغم من أن معظم مترجمي معاني القرآن إلى اللغة الأسبانية من مسلمين وغير مسلمين يدعون الأخذ بما جاءت به التفاسير في نقلهم المعاني القرآنية إلى الأسبانية لكن لسان الحال أي ترجمتهم، يقول عكس ذلك. ومن الممكن القيام بأطروحة دكتوراه بتدوين ودراسة هذه الأخطاء في ترجمات معاني القرآن إلى اللغة الاسبانية التي، على الغالب، أخطاءخالية من العدل عند مراجعة تفاسير الذكر الحكيم.

وفي ترجمة معاني القرآن الكريم يؤدي كل من التفسير والتأويل دورهما الخاص،المتمثل في أن يزود مضمون التفسير القرآني الرواية، أي بجلّ المعلومات التي تمكن من توثيق المعنى المقصود في سياق آيات القرآن، ويوحي التأويل بالأسلوب الأنسب لنقل معاني الآيات والسور إلى اللغة المترجم إليها، وذلك فضلا عنأن التأويل يأتي كذلك بتوثيق المعنى المقصود بالألفاظ والتراكيب القرآنية. وهكذا وفي عملية ترجمة معاني القرآن يضمن تفسير القرآن أبعاد الرواية في فهم النص في الوقت الذي يؤمن التأويل ويشجع إمكانيات الدراية في نقله إلى اللغة المترجم إليها. ويميل الدكتور الذهبي إلى الرأي القائل بأن فهم القرآن يستلزم الاعتماد على التفسير بمعنى الرواية، وعلى التأويل بمعنى الدراية في استتباط الفوائد منه. وهذا رأي يستحق الأخذ به في قضية ترجمة معاني القرآن بمعنى أن يتم فهم القرآن بفضل التفسير والتأويل معا من أجل العثور على أوفى طريقة لنقل المعنى من العربية إلى لغات أخرى نظرا إلى ما يوفر التأويل من أوجه التحليل وسبل الشرح والتفهيم. وفي ذلك يقول الدكتور الذهبي (التفسير

$$
\text { والمفسرون: 2005، ج } 1 \text { ص 24): }
$$

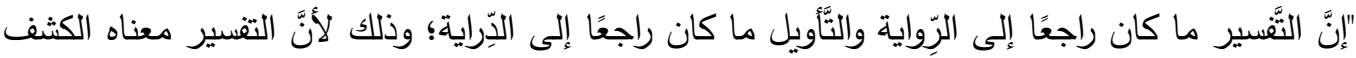
عن مراد الله تعالى لا نجزم به إلا إذا ورد عن رسول الله -عليه السلام- أو عن بعض أصحابه الذين شهدوا نزول الوحي وعلموا ما أحاط به من حوادث ووقائع، وخالطوا رسول الله، صلى الله عليه وسلم، ورجعوا إليه فيما أشكل عليهم من معاني القرآن. 
[...] وأما التأويل فملحوظ فيه ترجيح أحد محتملات اللفظ بالدليل والترجيح يعتمد على الاجتهاد ويتوصل إليه بمعرفة مفردات الألفاظ ومدلولاتها في لغة العرب واستعمالها بحسب السياق ومعرفة الاساليب العربية واستتباط

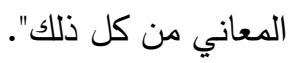

وهذا الرأي مستوحى من كلام الزركشي الذي يوضح كثرة الاصطلاح في مفهومي التفسير والتأويل في القرآن بين المفسرين بقوله (للبرهان في علوم القرآن: ج 2 ص 182): "وكان السبب في اصطلاح كثير من التفرقة بين التقسير والتأويل التمييز بين المنقول والمستتبط ليحيل على الاعتماد في المنقول وعلى النظر في المستنبط تجويزًا لله وازديادًا، وهذا من الفروع في الدين".

وفي تفسير معاني القرآن وتأويلها مرجعان لتنفيذ عملية الترجمة والحصول على التوازن المطلوب بين احترام أساليب التعبير في النص الأصلي وطريقة أدائها في اللغة المترجم إليها بلباقة تتاسب المذاق الأدبي فيها. وكل ذلك بغية الوفاء بالمعنى والتلميح إلى خصائص الصياغة اللغوية في النص المصدر للترجمة ولو من باب الاقتراب إلى ما له استحالة مثل ترجمة معاني القرآن على كمال تام.

وهناك أمر من غير الملائم غيابه عنَّا، وذلك أن ترجمة معاني القرآن، مثل ما هي حال سائر الترجمات ولو باختلاف في الدرجة والأهمية، تثري الرصيد اللغوية في اللغات المترجم إليها، وفي الوقت نفسه تثنيل تثري الأفكار

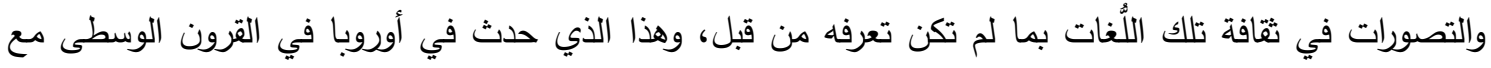
ترجمات الكتب الإسلامية باستثناء القرآن الذي كانت ممنوعة قراءته وترجمته، وحتى تداوله باللغة العربية في

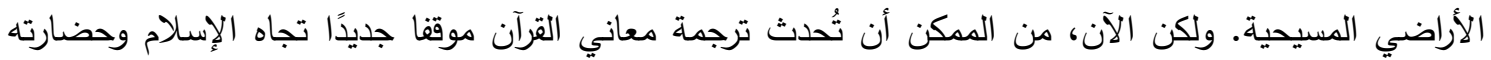
وتاريخه ومجتمعاته، وحتى إزاء الإنسان بنفسه مع استخدام التفاسير القديمة والحديثة وبحوث الإعجاز القدئ القرآني.

فتقسيره يذكرنا دائما بأسلوب القرآن المعزز، والذي يرشدنا إلى البحث عن أسلوب مقارب في اللغة المترجم إليها؛ لتصوير طريقة القرآن في الإخبار والقصص والحكم ومعالجة شتى المواضيع المعروضة فيه. وأما التأويل فإنه يدفعنا إلى إبداع الصياغة في اللغة المترجم إليها، لإفساح المجال فيها للتعبير القرآني وأفكاره بصيغة مستساغة ومقبولة نحوا ولغة وبلاغة.

"ينقسم عادة مترجمو الأدب ما بين مترجمين "أصلويين" [محافظين]، ومترجمين إبداعيين، ويجتها المترجمون الأصوليُّن في نقل صيخ النَّص الأصليّ إلى اللُّة المترجم إليها في أقرب قالب ممكن للقالب الأصلي. أما المترجمون الإبداعيون فثغلهم الثاغل هو، على الغالب، إبداع نص ذي نغم مطرب في اللغة المترجم إليها، ولا يبالون بدقة نقل الألفاظ [إلا بما يقتضيه الوفاء للمعنى]. وعلى كل مترجم نجيب الوقوف بين الطرفين [...] فليست الترجمة، كما كتب بيريار، نقل المعاني من لغة إلى أخرى بل حوار جار بين لسانين" (أديث غروسمان: لماذا هناك (هتمام بالترجمة؟ : 2011، ص 62). 
وفيما يخصُ القرآن فلا مناص من احترام المعاني الأصلية بأدق الدقة في نقلها إلى اللغة المترجم إليها، مع الاجتهاد في تقديمها بأسلوب يستسيغه القارئ والسامع الناطقين بتلك اللغة بغرض إلهامهما بشيء، مما شعر أول من سمع وقرأ القرآن بالعربية وما زال يشعر القارئ والسامع العربيان والمسلمون منهما على الأخص. فلجميع خصائص القرآن دور في تخطيط عملية الترجمة وجل هذه الخصائص قد تتاولتها التفاسير القرآنية، ومن ذا على مترجم معاني القرآن، الاعتبار بها واستعمالها قدر المستطاع في الإتيان بها في اللغة الأجنبية المستهدفة في الترجمة. ومن الظريف والمفيد في ذلك، ذكر ما قاله عبد الله بن مسعود في تفسيره عن الآية (121) لسورة البقرة

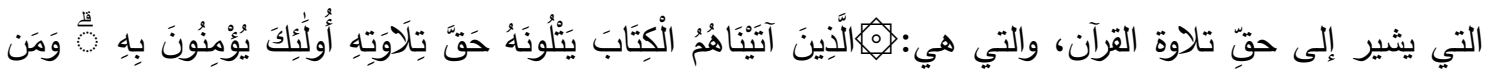

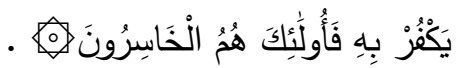
وذلك لأنَّ هذا الكلام لابن مسعود تجوز إحالته من تلاوة القرآن إلى ترجمة معانيه: "والذي نفسي بيده، إنَّ حقَّ تلاوته [وحق ترجمة معانيه] أن يحل حلاله ويحرم حرامه، ويقراه كما أنزله الله، ولا يحرف الكلم عن موضعه، ولا يتأول منه شيء على غير تأوليه"(تفسير /بن كثير : 1981، ج 1 ص 164).

• أبو حيان الأندلسي، محمد بن يوسف (2010): البحر المحيط، دراسة وتحقيق وتعليق الثيخ عادل أحمد عبد الموجود والثيخ على محمد معوض والدكتور زكاريا عبد المجيد النوتي والدكتورأحمد النجولي الجمل، دار الكتب العلمية، بيروت.

•- ابن خلدون، عبد الرحمن بن محمد (دون سنة): مقدمة /بن خلدون، تحقيق: د. علي عبد الواحد وافي، نهضة مصر للطباعة والنشر والتوزيع. - ابن كثير ، إسماعيل بن عمر (1981): تفسير /بن كثير، دار الفكر، بيروت •- طبيبي، عبد الحكيم (1986): تتسير القرآن الكريم وترجمته"، في الندوة العالمية حول ترجمات معاني القرآن الكريم، أسنتبول، جمعية الدعوة الإسلامية العالمية في ليبيا.

•- الجاحظ، أبو عثمان عمر بن بحر (دون سنة): كتاب الحيوان، تحقيق وشرح: عبد السلام محمد هارون، دار الجيل، بيروت. •- ذاكر ، عبد النبي (1998): قضايا ترجة القرآن، سلسلة شراع، وكالة شراع لخدمات الإعلام والاتصال، طنجة. . - الذهبي، محمد حسين (2005): التفسير والدفسرون، دار الحديث، القاهرة. 
•- الزركثي، بدر الدين محمد بن عبد الله (دون سنة): البرهان في علوم القرآن، تحقيق: محمد أبو الفضل إبراهيم، مكتبة التراث، القاهرة. • سعيد، إدوارد ( 1990): الاستشرق (ترجمة إسبانية لماريا لويسا فوانتيس)، المنشورات التحررية، مدريد. •- الثاطبي، أبو إسحاق إبراهيم بن موسى (1996/1416): الموافقات في أصول الثريعة، دار المعرفة، بيروت. •- غروسمان، أديث (2011): لماذا هناك /هتمام بالترجمة؟ (ترجمة إسبانية لألفيو إ. جندولفو)، كاتز للنشر، بوانوس ايريس، الأرجنتين. •- نيدا، أويجين (1986): الترجمة في تنظيرها وتطبيقها (ترجمة إسبانية لألفونسو دي لا فوانتي أدانيث)، منشورات المسيحية، مدريد. 